\title{
Inhibition of LDHA suppresses cell proliferation and increases mitochondrial apoptosis via the JNK signaling pathway in cervical cancer cells
}

\author{
WENJING ZHANG ${ }^{1,2}$, CUI WANG ${ }^{1}$, XIAOMEI HU ${ }^{1}$, YANZHEN LIAN ${ }^{1}$, CAILI DING $^{3}$ and LIANG MING ${ }^{1,2}$ \\ ${ }^{1}$ Department of Clinical Laboratory, The First Affiliated Hospital of Zhengzhou University; \\ ${ }^{2}$ Key Clinical Laboratory of Henan Province, Zhengzhou, Henan 450052; \\ ${ }^{3}$ Zhengzhou Hang Gang Ding Shi Medical Laboratory Co., Ltd., Zhengzhou, Henan 450000, P.R. China
}

Received November 4, 2021; Accepted January 28, 2022

DOI: $10.3892 / o r .2022 .8288$

\begin{abstract}
The Warburg effect or aerobic glycolysis is a hallmark of cancer. Lactate dehydrogenase (LDH), which catalyzes conversion of pyruvate into lactate, serves a critical role during Warburg effect. LDH A chain (LDHA), a member of the LDH family, is upregulated in multiple types of cancer and serves a vital role in tumor growth and progression. However, its expression and function in cervical cancer has not been characterized. The present study evaluated LDHA expression in The Cancer Genome Atlas database and found that LDHA was upregulated in cervical cancer compared with normal tissue. To clarify the role of LDHA in cervical cancer HeLa and SiHa cells, lentiviral shRNA was used to stably knockdown LDHA and oxamate, a small-molecule inhibitor of LDHA, was used to inhibit the activity of LDHA. Glucose uptake assay, lactate production measurement and ATP detection assay demonstrated LDHA inhibition notably decreased glucose consumption, lactate production and ATP levels in both HeLa and SiHa cells. Furthermore, the effect of LDHA inhibition on cell proliferation, cell cycle and apoptosis was investigated by MTT, BrdU incorporation, colony formation assay, flow cytometry and western blotting; LDHA knockdown or oxamate treatment led to decreased cell proliferation and increased apoptosis. Inhibition of LDHA induced $\mathrm{G}_{2} / \mathrm{M}$ cell cycle arrest and activated the mitochondrial apoptosis pathway. Mechanistically, the JNK signaling pathway was key for LDHA inhibition-mediated cell cycle arrest and apoptosis. Collectively, these results indicated that LDHA was involved in cervical cancer pathogenesis and may be a promising therapeutic target for treatment.
\end{abstract}

Correspondence to: Professor Liang Ming, Department of Clinical Laboratory, The First Affiliated Hospital of Zhengzhou University, 1 Jianshe East Road, Zhengzhou, Henan 450052, P.R. China E-mail: mingliang3072@163.com

Key words: Warburg effect, lactate dehydrogenase A chain, cervical cancer, cell proliferation, apoptosis

\section{Introduction}

Cervical cancer is the second most common type of cancer and one of the most common types of gynecological malignancy in women worldwide (1-3) with 500,000 new cases and 270,000 deaths in 2018 (4). In China, the average age range is 30-35 years for onset of cervical cancer and 45-55 years for invasive cancer (5). Investigation of the molecular mechanisms that promote the pathogenesis of cervical cancer is needed.

Cancer cells produce energy by taking up glucose and converting it to lactate, even under experimental conditions with sufficient oxygen. This was first described by Otto Warburg in 1924 and was called the Warburg effect or aerobic glycolysis $(4,6,7)$. Cancer cells obtain enough energy and biosynthetic precursors (such as nucleotides, proteins and lipids) via the Warburg effect to achieve enhanced proliferation, survival and long-term maintenance (8).

Accumulating evidence has demonstrated that aerobic glycolysis is a key hallmark of cancer cells $(9,10)$; molecules involved in the aerobic glycolysis pathway may be potential targets in cancer therapy, including cervical cancer $(7,11)$. Therefore, certain metabolic enzymes such as Hexokinase 2, Phosphoinositide-Dependent Kinase 1 and Lactate dehydrogenase A chain (LDHA) involved in aerobic glycolysis have been identified as potential therapeutic targets (12-15).

LDH is a key enzyme in aerobic glycolysis that catalyzes interconversion of lactate and pyruvate, accompanied by interconversion of NADH and $\mathrm{NAD}^{+}(16)$. $\mathrm{LDH}$ is a tetramer composed of two subunits: muscle- and heart-type, encoded by LDHA and LDHB (17). LDHA is abnormally expressed in multiple types of human cancer, including renal (14), gastric (18) and pancreatic $(19,20)$, hepatocellular (21) and nasopharyngeal carcinoma (22), as well as breast cancer (23). Furthermore, studies have indicated that inhibition of LDHA decrease tumor proliferation in numerous types of cancer cell, such as renal and breast cancer and human hepatocellular and nasopharyngeal carcinoma cells $(14,21,22,24,25)$. LDHA inhibition suppresses migration of cancer cells and increases radiosensitivity and chemosensitivity $(19,22,26,27)$. However, the underlying roles and mechanism of LDHA in cervical cancer are largely unknown. 
The present study aimed to verify expression of LDHA in human cervical cancer. Furthermore, the effect of LDHA inhibition by oxamate, a classic inhibitor of LDHA $(28,29)$, or short hairpin (sh)RNA on cervical cancer cells was investigated. The purpose of the present study was to determine the effect of LDHA inhibition on metabolism, proliferation and apoptosis of cervical cancer cells and to investigate the underlying mechanism.

\section{Materials and methods}

Cell lines, reagents and antibodies. Human cervical squamous cell carcinoma and endocervical adenocarcinoma (CESC; $\mathrm{HeLa}$ and $\mathrm{SiHa}$ ) and $293 \mathrm{~T}$ cell lines were obtained from American Type Culture Collection, which had characterized the cell lines by short tandem repeat profiling, cell morphology and karyotyping assay. The cell lines were maintained in RPMI-1640 supplemented with $10 \%$ fetal bovine serum (both Gibco; Thermo Fisher Scientific, Inc.) at $37^{\circ} \mathrm{C}$ in $5 \% \mathrm{CO}_{2}$. Oxamate was purchased from Sigma-Aldrich (Merck KGaA). SP600125 was purchased from Abcam. For JNK inhibitor assay, HeLa cells were treated with $10 \mu \mathrm{M}$ SP600125 $1 \mathrm{~h}$ at $37^{\circ} \mathrm{C}$ prior to oxamate treatment and cells were incubated for another $48 \mathrm{~h}$ at $37^{\circ} \mathrm{C}$. LDHA-knockdown HeLa cells were treated with $10 \mu \mathrm{M}$ SP600125 for $48 \mathrm{~h}$ at $37^{\circ} \mathrm{C}$. The primary antibodies for LDHA, cleaved caspase-3, caspase-9, Cyclin A, Cyclin B1, p21, cyclin-dependent kinase (CDK)1, JNK, phosphorylated (p-)JNK, p38 and p-p38 were obtained from Cell Signaling Technology, Inc. The antibody for $\beta$-actin was purchased from Santa Cruz Biotechnology, Inc. The antibodies for cytochrome $c$ and cytochrome $c$ oxidase IV (COX IV) were obtained from Abcam.

Bioinformatics analysis. Gene Expression Profiling Interactive Analysis (GEPIA; gepia.cancer-pku.cn/index.html) comprises open databases for analysis of gene expression data from The Cancer Genome Atlas (TCGA; cancer.gov/tcga) (30). GEPIA was used to analyze mRNA expression levels of LDHA in human tumor and normal samples, the correlation between LDHA and mitochondrial pyruvate carrier 1 (MPC1) and the potential prognostic value of LDHA expression levels. Data were extracted from TGGA.

Cytotoxicity assay. HeLa and SiHa cells were seeded at 10,000 cells/well in triplicate in 96 -well plates for $24 \mathrm{~h}$ at $37^{\circ} \mathrm{C}$, then treated with $10,20,50,80$ and $100 \mathrm{mM}$ oxamate for $44 \mathrm{~h}$ at $37^{\circ} \mathrm{C}$. Cytotoxicity of oxamate was measured using MTT Cell Proliferation and Cytotoxicity Assay kit (cat. no. M1020; Beijing Solarbio Science \& Technology Co., Ltd.) according to the manufacturer's protocol. MTT solution was added to each well and incubated for $4 \mathrm{~h}$ at $37^{\circ} \mathrm{C}$ in a humidified atmosphere. MTT formazan precipitate was dissolved in dimethyl sulfoxide. Absorbance was measured at $570 \mathrm{~nm}$. In addition, viability of LDHA knockdown and control cells were also measured by MTT detection kit as aforementioned.

BrdU incorporation assay. LDHA knockdown or oxamate-treated HeLa and SiHa cells were incubated with BrdU for $6 \mathrm{~h}$ at $37^{\circ} \mathrm{C}$. BrdU uptake was analyzed by
Cell Proliferation ELISA, BrdU (colorimetric) assay (cat. no. 11647229001; Roche Diagnostrics) according to the manufacturer's protocol.

Colony formation assay. For colony formation assay, 1,000 cells from LDHA knockdown or oxamate-treated HeLa and SiHa groups were plated in six-well plates and cultured for 7 days at $37^{\circ} \mathrm{C}$. The cells were fixed in $4 \%$ paraformaldehyde solution for $15 \mathrm{~min}$ at room temperature and stained with $0.1 \%$ crystal violet solution for $10 \mathrm{~min}$ at room temperature. Then, colonies ( $>50$ cells/colony) were observed using a light microscope (magnification, x40; Olympus Corporation), counted by using the ImageJ Lab software (version k1.7.9; National Institutes of Health), photographed by using a Canon EOS600D digital camera (Canon, Inc.).

ATP detection assay. ATP levels in HeLa and SiHa cells were determined using ATP Assay Kit (cat. no. S0026; Beyotime Institute of Biotechnology) according to the manufacturer's protocol and as previously described $(31,32)$. In brief, samples were lysed with $200 \mu \mathrm{l}$ lysis buffer, centrifuged at $6,000 \mathrm{~g}$ for $5 \mathrm{~min}$ at $4^{\circ} \mathrm{C}$ and the supernatant was collected. Then, the supernatant was mixed with $100 \mu \mathrm{l}$ ATP detection working buffer and measured by a plate-reading luminometer.

Lactate production measurement. Lactate production was determined by Lactic Acid assay kit (cat. no. A019-2-1; Nanjing Jiancheng Bioengineering Institute) as previously described (33). Briefly, HeLa and SiHa cells were harvested, washed twice with PBS and lysed in RIPA buffer (cat. no. 89900; Thermo Fisher Scientific) for $30 \mathrm{~min}$ on ice. Following centrifugation at $6,000 \mathrm{~g}$ for $10 \mathrm{~min}$ at $4^{\circ} \mathrm{C}$, the supernatant was collected in microcentrifuge tubes, mixed with an equal volume of substrate and incubated at $37^{\circ} \mathrm{C}$ for $10 \mathrm{~min}$. Following the addition of stop solution, each sample (volume, $200 \mu \mathrm{l}$ ) was aliquoted in the wells of a 96-well microtiter plate. Lactate concentration was evaluated by measuring absorbance using a microplate reader at $530 \mathrm{~nm}$. The result was normalized to the total protein content, determined by BCA assay.

Glucose assay. Glucose Assay kit (cat. no. 361500; Shanghai Rongsheng Biotech Co., Ltd.) was used to detect the glucose uptake according to the manufacturer's instructions and quantified by measuring the absorption at $450 \mathrm{~nm}$. HeLa and $\mathrm{SiHa}$ cells were cultured in 96-well plates seeded at 10,000 cells/well in RPMI-1640 (Gibco; Thermo Fisher Scientific, Inc.) for $24 \mathrm{~h}$ at $37^{\circ} \mathrm{C}$, then treated with oxamate for $24 \mathrm{~h}$. The cells were centrifuged at $6,000 \mathrm{~g}$ for $10 \mathrm{~min}$ at $4^{\circ} \mathrm{C}$ and the supernatant was collected. Glucose uptake was calculated as follows: original glucose concentration in medium-detected glucose concentration in culture supernatant.

Transfection of CESC cells with LDHA shRNA lentiviral vector. shRNA sequences targeting LDHA were as follows: shRNA1, 5'-GATCCCCACCATGATTAAGGGTCTTTC TTCCTGTCAGAAAAGACCCTTAATCATGGTGGTTTT TG-3' and shRNA2, 5'-GATCCGCAAACTCCAAGCTGG TCATTCTTCCTGTCAGAAATGACCAGCTTGGAGTTT GCTTTTTG-3'. The shRNA sequence of the negative control (PGreenpuro shRNA) was 5'-GATCCGTGCTCCACGGCA 
TTTCATTACTTCCTGTCAGATAATGAAATGCCGTGG AGCACTTTTTG-3'. pGreenPuro-LDHA-shRNA1 and pGreenPuro-LDHA-shRNA 2 were prepared by inserting target sequences into PGreenpuro shRNA vectors. pGreenPuro-LDHA-shRNA1, pGreenPuro-LDHA-shRNA 2 and PGreenpuro shRNA were obtained from Chengdu Transvector Biotechnology. The concentration of extracted plasmid was $>500 \mathrm{ng} / \mu \mathrm{l}$ with an A260/280 ratio of 1.8-2.0. A second generation lentivirus packaging system was used. The plasmid pGreenPuro-LDHA-shRNA $(2 \mu \mathrm{g})$ was co-transfected into $293 \mathrm{~T}$ cells together with packaging vectors psPAX2 $(2 \mu \mathrm{g})$ and envelop plasmids pMD2.G $\left(1.5 \mu \mathrm{g}\right.$; both Addgene, Inc.) using Lipofectamine ${ }^{\circledR} 2000$ (Invitrogen; Thermo Fisher Scientific, Inc.) according to the manufacturer's instructions. The viral supernatant fraction was collected at $48 \mathrm{~h}$ post-transfection and filtered through a $0.45 \mu \mathrm{m}$ filter. Viral titers were determined by QuickTiter Quantitation kit (Cell Biolabs, Inc.) according to the manufacturer's instructions. Multiplicity of infection of 50 and 60 were used for HeLa and SiHa cells, respectively. HeLa and $\mathrm{SiHa}$ cells were co-cultured with viral supernatant and $6 \mu \mathrm{g} / \mathrm{ml}$ polybrene for $16 \mathrm{~h}$ at $37^{\circ} \mathrm{C}$. Then, RPMI-1640 (Gibco; Thermo Fisher Scientific, Inc.) was replaced with fresh medium. After $24 \mathrm{~h}$, the medium was replaced with fresh RPMI-1640 medium (Gibco; Thermo Fisher Scientific, Inc.) containing $1 \mu \mathrm{g} / \mathrm{ml}$ puromycin (Thermo Fisher Scientific, Inc.). The cells were maintained in medium with $1 \mu \mathrm{g} / \mathrm{ml}$ puromycin for 2 weeks at $37^{\circ} \mathrm{C}$.

Analysis of cell cycle distribution and apoptosis. For cell cycle analysis, $\mathrm{HeLa}$ and $\mathrm{SiHa}$ cells were collected following treatment with $20 \mathrm{mM}$ oxamate for $48 \mathrm{~h}$ at $37^{\circ} \mathrm{C}$, then fixed with $4 \%$ paraformaldehyde at $4^{\circ} \mathrm{C}$ for $30 \mathrm{~min}$. Following washing with PBS three times, cells were stained with propidium iodine (PI; $50 \mu \mathrm{g} / \mathrm{ml}$; cat. no. P2667; Sigma-Aldrich; Merck KGaA) at room temperature for $30 \mathrm{~min}$ in the dark according to the manufacturer's instructions. Cell cycle distribution was analyzed using 10,000 cells by flow cytometry analysis using a FACS Canto II flow cytometer (Becton, Dickinson and Company) and BD FACS DIVA software, version 6.1.3 (Becton-Dickinson and Company). For apoptosis assay, HeLa and $\mathrm{SiHa}$ cells were harvested, washed with PBS, stained with $5 \mu \mathrm{l}$ Annexin V-FITC and $5 \mu \mathrm{l}$ PI at room temperature for 15 min using FITC Annexin V Apoptosis Detection kit (cat. no. 556547; BD Biosciences) and analyzed by FACSCanto II flow cytometer as previously described (34). Apoptotic rate was calculated as follows: Late apoptosis cell number/total cell number $\mathrm{x} 100 \%$.

Western blot analysis. HeLa and SiHa cells were harvested and washed with PBS. The protein was were extracted and western blot analysis was performed as previously described (35). Mitochondria were isolated from cells using Mitochondria Isolation Kit for Cultured Cells (TransGen Biotech Co., Ltd.) according to the manufacturer's protocol. Total protein was extracted from cells using Mammalian Total Protein Extraction kit (TransGen Biotech Co., Ltd.) according to the manufacturer's protocol. Enhanced BCA Protein Assay kit (cat. no. P0010; Beyotime Institute of Biotechnology) was used to determine protein concentration. Then, $12 \%$ separation and 5\% stacking gels were prepared for electrophoresis. The proteins $(20 \mu \mathrm{g} / \mathrm{lane})$ were separated and transferred onto PVDF membranes (EMD Millipore) via wet transfer method. Next, $5 \%$ skimmed milk in $1 \mathrm{X}$ Tris-buffered saline- $0.05 \%$ Tween-20 (TBST; Beijing Solarbio Science \& Technology Co., Ltd.), was used to block membranes at room temperature for $1 \mathrm{~h}$. The membranes were incubated with primary antibodies against LDHA (cat. no. 3582; 1:1,000), Cyclin A (cat. no. 67955; 1:1,000), Cyclin B1 (cat. no. 12231; 1:1,000), p21 (cat. no. 2947; 1:1,000), CDK1 (cat. no. 28439; 1:500), p38 (cat. no. 8690; 1:1,000), p-p38 (cat. no. 4511; 1:1,000), JNK (cat. no. 9252; 1:1,000), p-JNK (cat. no. 9255; 1:2,000), cleaved-caspase-3 (cat. no. 9664; 1:1,000), caspase-3 (cat. no. 14220; 1:1,000; Cell Signaling Technology, Inc.), cleaved-caspase-9 (cat. no. 20750; 1:1,000; Cell Signaling Technology, Inc.), caspase-9 (cat. no. 9508; $1: 1,000$ ), $\beta$-actin (cat. no. 4778; 1:2,000), cytochrome $c$ (cat. no. ab133504; 1:5,000) and COX-IV (cat. no. ab202554; $1: 2,000)$ overnight at $4^{\circ} \mathrm{C}$. The membranes were washed with $1 \mathrm{X}$ TBST for $5 \mathrm{~min}$ ( 3 times). Horseradish peroxidase-conjugated goat anti-rabbit (cat. no. 7074; 1:2,000; Cell Signaling Technology, Inc.) and anti-mouse antibody (cat. no. 7076; 1:2,000; Cell Signaling Technology, Inc.) were used as secondary antibodies. The membranes were incubated with secondary antibodies at room temperature for $1 \mathrm{~h}$ and washed with $1 \mathrm{X}$ TBST for $5 \mathrm{~min}$ (3 times). The membranes were visualized using Luminata ${ }^{\mathrm{TM}}$ Crescendo Western HRP Substrate (EMD Millipore). Protein expression was quantified using ImageJ Lab software (version k1.7.9; National Institutes of Health).

Statistical analysis. All data were presented as the as mean \pm SD of $\geq 3$ independent experimental repeats. The overall survival curve was generated and assessed via Kaplan-Meier and log-rank tests. Correlation analysis was performed using Pearson correlation analysis. Data containing two groups were analyzed by unpaired Student's t-test and two-tailed distribution. Data containing $>2$ groups was analyzed by one-way ANOVA followed by Tukey's post-hoc test. Data were analyzed using SPSS 18.0 (SPSS, Inc.) and GraphPad Prism 5.0 software (GraphPad Software, Inc.). ${ }^{*} \mathrm{P}<0.05$ was considered to indicate a statistically significant difference.

\section{Results}

LDHA is upregulated in cervical cancer and associated with patient survival. To determine the gene expression of LDHA in human tumor and normal samples, TCGA datasets were analyzed via GEPIA. LDHA gene expression levels were upregulated in most types of tumor, including CESC, compared with normal tissue (Fig. 1A). Furthermore, analysis of TCGA data using GEPIA showed a significantly higher LDHA gene expression in CESC compared with normal cervical tissue (Fig. 1B). In addition, tumor samples were separated into low and high groups based on median expression level of LDHA. LDHA overexpression was significantly associated with shorter overall survival in patients with cervical cancer (HR=1.7; Fig. 1C), suggesting that high LDHA expression was a risk factor for poor prognosis in cervical cancer. These results suggesting that LDHA may play a critical role in cerivical cancer progression. Because of the key 
A

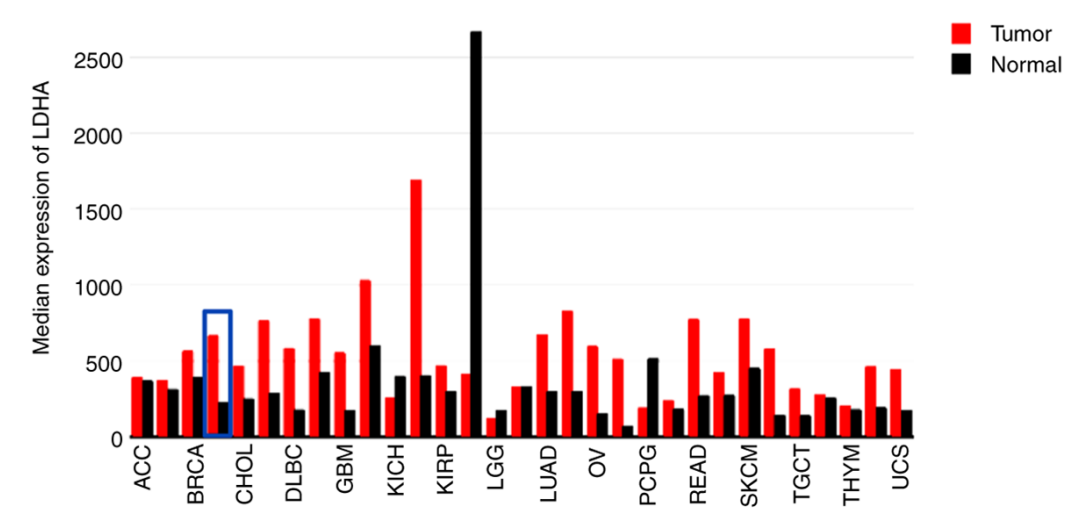

C
B

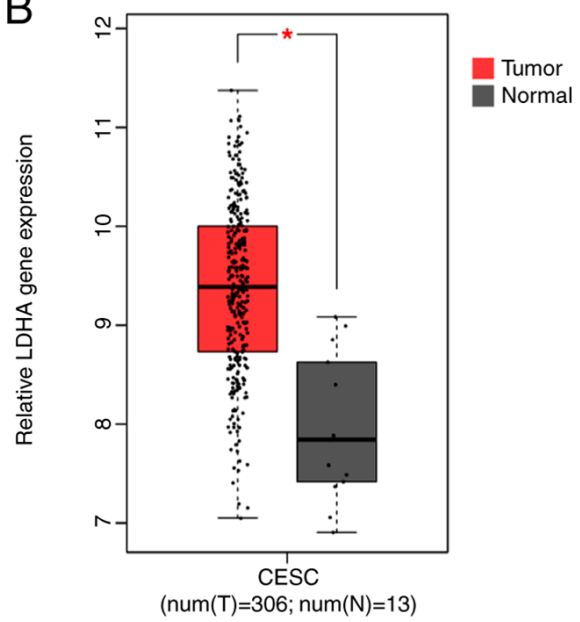

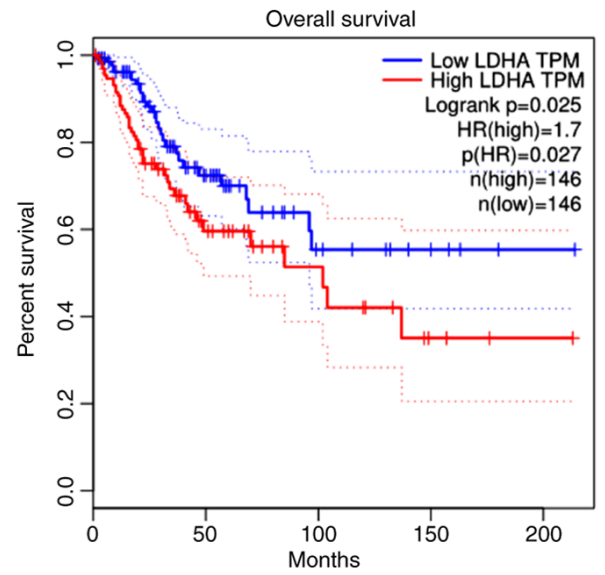

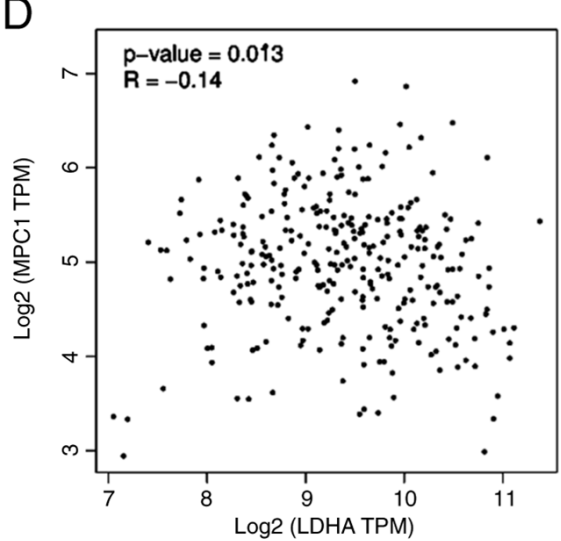

Figure 1. Expression levels of LDHA in cervical cancer and association with survival of patients with cervical cancer. (A) Pan-cancer analysis of mean expression levels of LDHA in different types of T tissue, including CESC (blue box). FC $>2$ served as the cut-off value. (B) LDHA mRNA levels in N and cervical cancer tissue $(\mathrm{FC}>2 ; \mathrm{P}<0.01)$. ${ }^{*} \mathrm{P}<0.05$ vs. N. (C) Association between LDHA and overall survival in patients with cervical cancer. The median expression level of LDHA was set as a cut-off point. (D) Correlation between LDHA and MPC1 levels in cervical cancer tissue. Data were acquired from The Cancer Genome Atlas database and analyzed via Gene Expression Profile Interactive Analysis. T, tumor, N, normal; CESC, cervical squamous cell carcinoma and endocervical adenocarcinoma; MPC1, mitochondrial pyruvate carrier 1; LDHA, lactate dehydrogenase A chain; FC, fold-change; TPM, transcripts per million.

role of MPC1 in pyruvate metabolism, the association between LDHA and MPC1 was evaluated using GEPIA. Correlation analysis (Fig. 1D) showed that LDHA levels were negatively correlated with MPC1 ( $\mathrm{R}=-0.14)$, supporting the hypothesis that cervical cancer was aerobic glycolysis-dependent. Taken together, these results suggested that LDHA was upregulated in cervical cancer and dysregulation of LDHA served a key role in cervical cancer.

LDHA inhibition disrupts energy metabolism. As LDHA overexpression were negatively correlated with overall survival in patients with cervical cancer, the effect of LDHA inhibition on glycolysis in CESC cells was investigated. To determine the effect of LDHA inhibition on energy metabolism in CESC cells, oxamate, a small-molecule inhibitor of LDHA (36), was used. According to the concentrations of oxamate used in previous reports $(18,20,37)$, we selected 10 and $20 \mathrm{mM}$ oxamate for the energy metabolism study. Meanwhile, four stable LDHA-depleted CESC cell lines (HeLa and SiHa sh1 and sh2) were constructed to investigate the effect of knockdown on protein expression levels (Fig. 2A). The results indicated that sh1 and sh2 efficiently knocked down expression of LDHA compared with the control. Considering that the knockdown effect of sh1 was significantly greater compared with sh2 in both HeLa and SiHa cells, HeLa and SiHa sh1 cells were selected for further study. Intracellular biochemical indicators were detected in both HeLa and SiHa cells. Following treatment with oxamate for $24 \mathrm{~h}$, glucose uptake, lactate production and ATP levels decreased significantly in both HeLa and SiHa cells (Fig. 2B-D). Similarly, knockdown of LDHA in CESC cells decreased glucose uptake, lactate production and ATP levels (Fig. 2E-G). These results demonstrated that LDHA inhibition disrupted energy metabolism and suppressed the Warburg effect in CESC cells.

LDHA inhibition by oxamate suppresses proliferation of CESC cells. As increased glycolysis enables cancer cells to suppress apoptotic signaling and promotes viability and proliferation (38), the effect of LDHA on viability of CESC cells was assessed. Firstly, MTT assay was performed to investigate the cytotoxic effect of oxamate on CESC cells. HeLa and SiHa cells were treated with different doses of oxamate for $48 \mathrm{~h}$. Oxamate exhibited significant cytotoxicity toward these two CESC cancer cell lines in a dose-dependent manner (Fig. 3A and B). The $\mathrm{IC}_{50}$ value of oxamate for HeLa cells was $59.05 \mathrm{mM}$, while the $\mathrm{IC}_{50}$ value for $\mathrm{SiHa}$ cells was 
A
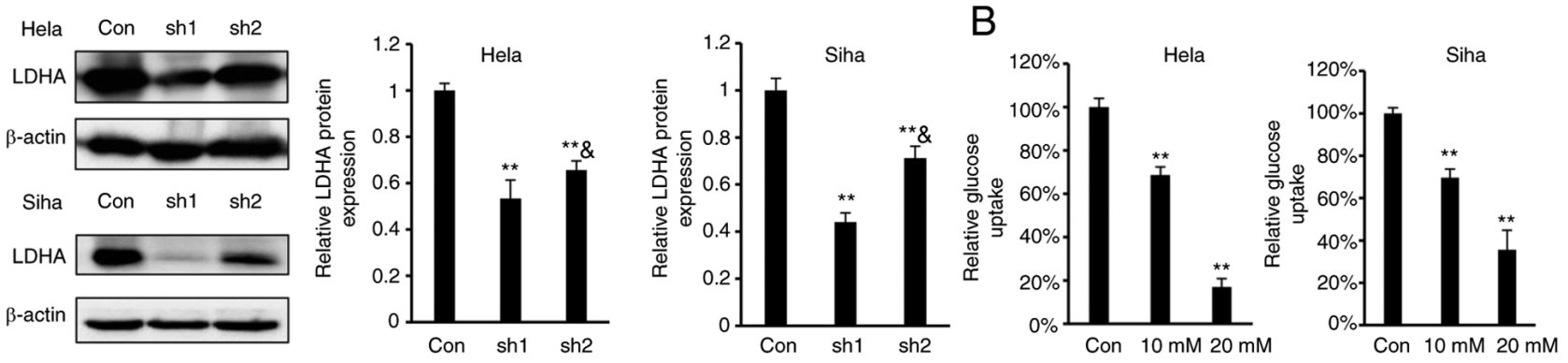

C
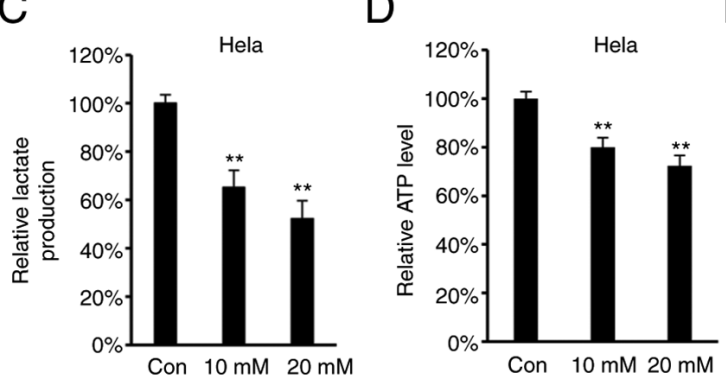

E

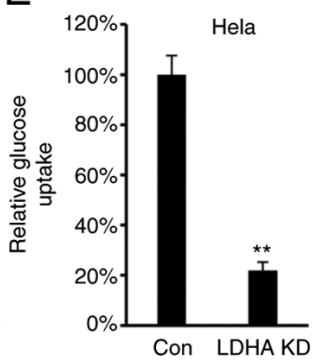

F

G
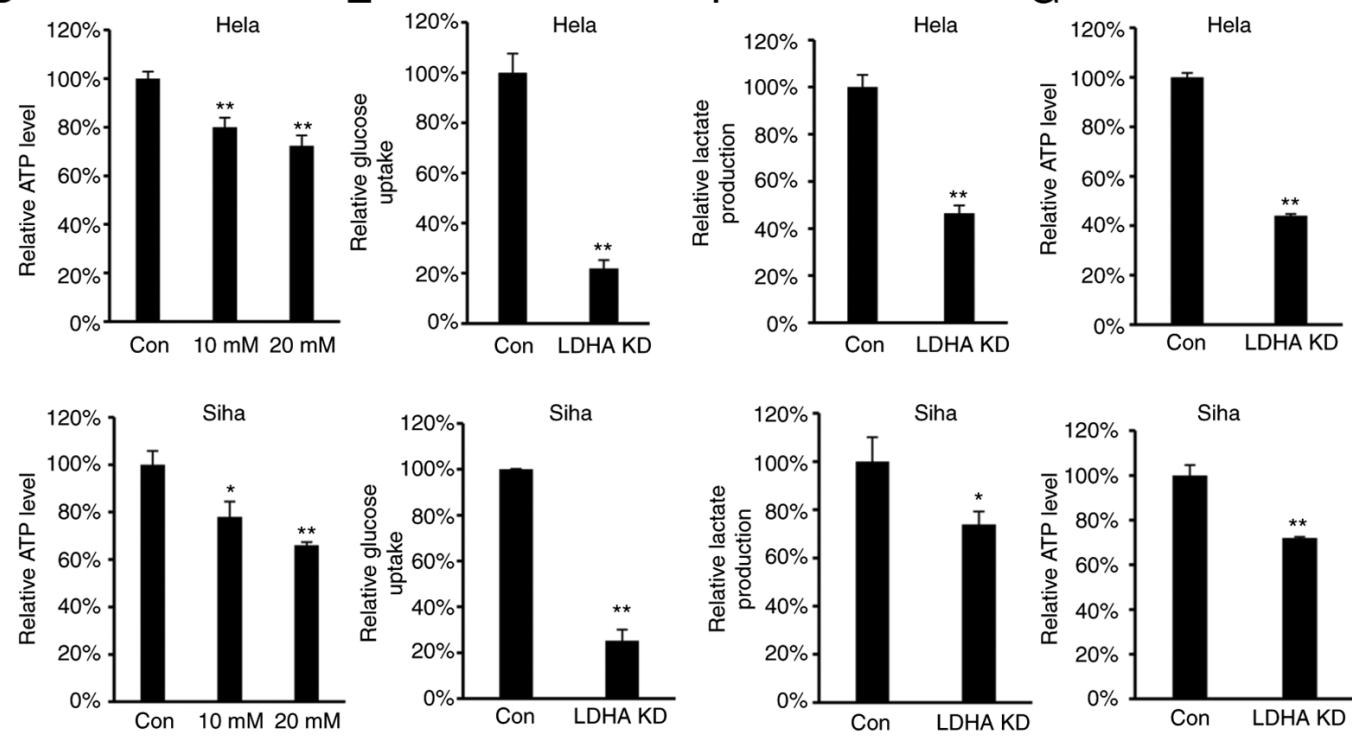

Figure 2. Regulation of ATP levels, glucose uptake and lactate production via inhibition of LDHA. (A) Levels of LDHA were detected by western blot analysis in LDHA-knockdown CESC (HeLa and SiHa sh1 and sh2) and con cells. ${ }^{* *} \mathrm{P}<0.01$ vs. con; ${ }^{\&} \mathrm{P}<0.05$ vs. \#sh1. (B) Glucose uptake, (C) lactate production and (D) intracellular ATP levels in HeLa and SiHa cells following treatment with oxamate for 24 h. (E) Glucose uptake, (F) lactate production and (G) ATP levels of LDHA-knockdown HeLa and SiHa cells. ${ }^{*} \mathrm{P}<0.05,{ }^{* *} \mathrm{P}<0.01$ vs. con. Con, control; sh, short hairpin; KD, knockdown; LDHA, lactate dehydrogenase A chain; CESC, cervical squamous cell carcinoma and endocervical adenocarcinoma.

$70.19 \mathrm{mM}$ (Fig. 3C). Cell proliferation was quantified by measuring BrdU incorporation (39); oxamate significantly inhibited proliferation of HeLa and SiHa cells (Fig. 3D and E). Clone formation assay showed that HeLa and SiHa cells formed significantly fewer clones following treatment with oxamate (Fig. 3F), suggesting that oxamate inhibited clone formation capacity in both HeLa and SiHa cells. Collectively, these results suggested that LDHA inhibition by oxamate in HeLa and SiHa cells inhibited proliferation.

LDHA inhibition by shRNA suppresses proliferation of CESC cells. To confirm the role of LDHA on proliferation of CESC cells, proliferation and viability of LDHA-knockdown CESC and control cells were investigated. Consistent with the aforementioned results, MTT assay showed that viability was significantly inhibited in all LDH-knockdown CESC cells (Fig. 4A and B). Furthermore, lower levels of BrdU incorporation were detected in $\mathrm{HeLa}$ and $\mathrm{SiHa} \#$ h1 cells compared with control (Fig. 4C and D). The clone formation assay demonstrated that LDHA knockdown inhibited clone formation capacity of HeLa and SiHa cells (Fig. 4E). In summary, similar to LDHA inhibition by oxamate, sh-induced LDHA knockdown suppressed viability, proliferation and colony forming ability of CESC cells.
Inhibition of LDH induces cell cycle arrest in $G_{2} / M$ phase. As LDHA inhibition suppressed proliferation of CESC cells, cell cycle distribution was investigated. The aforementioned data demonstrated that $20 \mathrm{mM}$ oxamate had a more significant effect than $10 \mathrm{mM}$ oxamate on cell survival, proliferation and metabolism; therefore, $20 \mathrm{mM}$ oxamate was used for cell cycle analysis. Cells were exposed to $20 \mathrm{mM}$ oxamate for $48 \mathrm{~h}$ and flow cytometry was used to analyze the cell cycle distribution following PI staining. There was an increase in the number of HeLa and SiHa cells in $\mathrm{G}_{2} / \mathrm{M}$ phase following treatment with oxamate (Fig. 5A and B). To verify the $G_{2} / M$ arrest induced by oxamate and determine the underlying mechanisms, western blot analysis was used to investigate changes in expression levels of proteins associated with $\mathrm{G}_{2} / \mathrm{M}$ transition (Fig. 5C and D). Protein levels of Cyclin B1, Cyclin $\mathrm{A}$ and CDK1 were significantly decreased in both SiHa and HeLa cells following treatment with oxamate, suggesting that oxamate induced $\mathrm{G}_{2} / \mathrm{M}$ arrest by modulating expression of Cyclin B1, Cyclin A and CDK1. Expression levels of proteins in upstream signaling pathways affecting cell cycle were also assessed; expression levels of p21 significantly increased following treatment with oxamate. These findings were consistent with inhibition of cell proliferation. The same results were found in both $\mathrm{SiHa}$ and HeLa cells following 

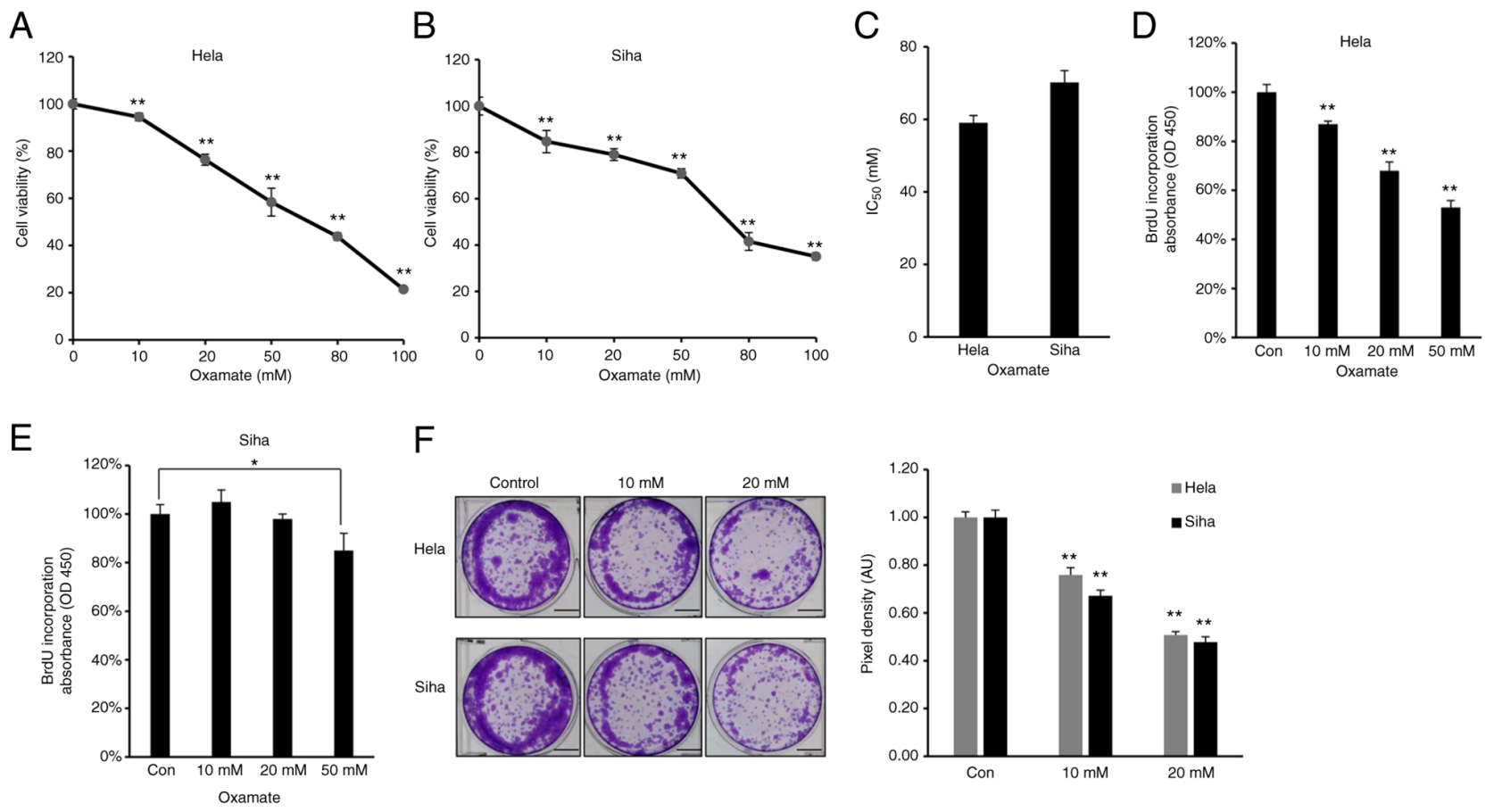

Figure 3. Lactate dehydrogenase A chain inhibition by oxamate suppresses viability of cervical squamous cell carcinoma and endocervical adenocarcinoma cells. Cytotoxicity of oxamate against (A) HeLa and (B) SiHa cells. (C) $\mathrm{IC}_{50}$ value of oxamate in HeLa and SiHa cells. BrdU incorporation assay was performed in (D) HeLa and (E) SiHa cells following treatment with oxamate. (F) Colony forming ability of HeLa and SiHa cells following treatment with oxamate. Bar, $40 \mathrm{~mm} .{ }^{*} \mathrm{P}<0.05,{ }^{* *} \mathrm{P}<0.01$ vs. con. Con, control; OD, optical density.

A

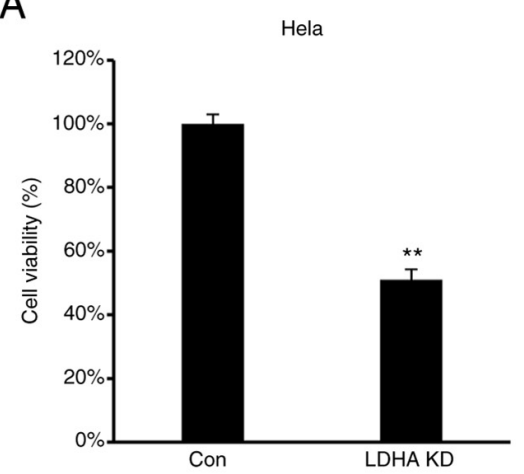

D

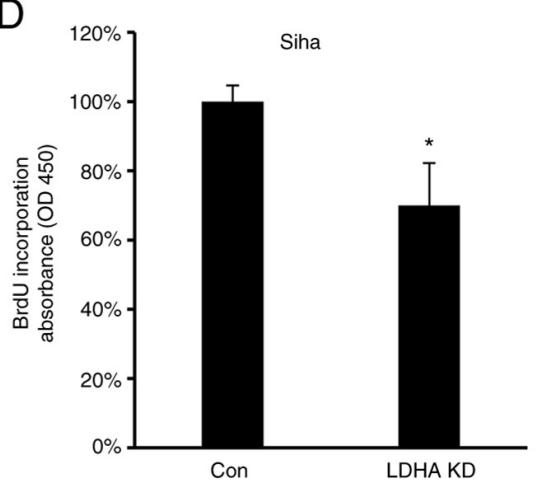

B

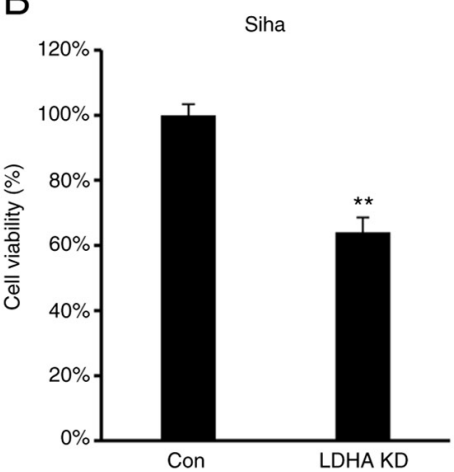

E

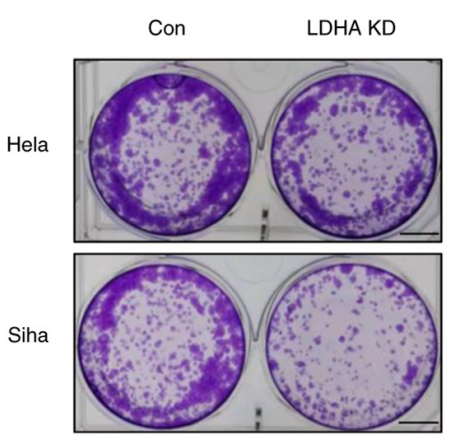

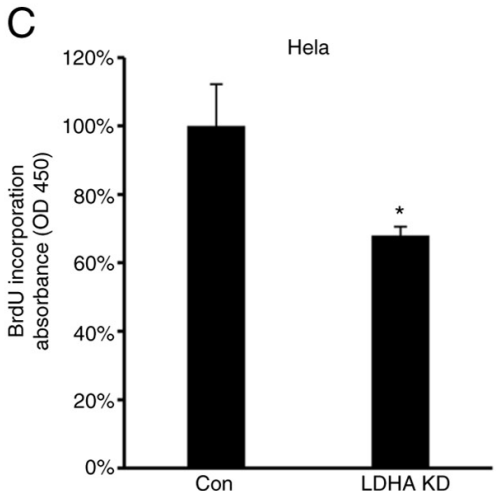

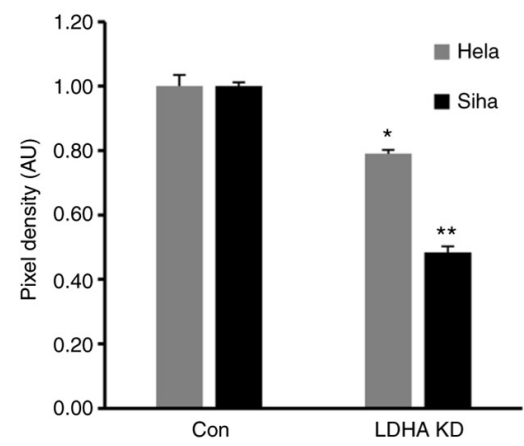

Figure 4. LDHA inhibition by short hairpin RNA suppresses proliferation of cervical squamous cell carcinoma and endocervical adenocarcinoma cells (A) HeLa and (B) SiHa cell viability was detected following LDHA KD. BrdU incorporation assay was performed in LDHA KD (C) HeLa and (D) SiHa cells. (E) Colony forming ability of LDHA KD HeLa and SiHa cells. Scale bar, $40 \mathrm{~mm}$. ${ }^{*} \mathrm{P}<0.05,{ }^{* *} \mathrm{P}<0.01$ vs. con. Con, control; KD, knockdown; LDHA, lactate dehydrogenase A chain; OD, optical density.

knockdown of LDHA (Fig. 5E and F). Collectively, these data indicated that LDHA inhibition in CESC cells induced cell cycle arrest, suggesting a tumor-suppressive role of LDHA in CESC cells. 
A
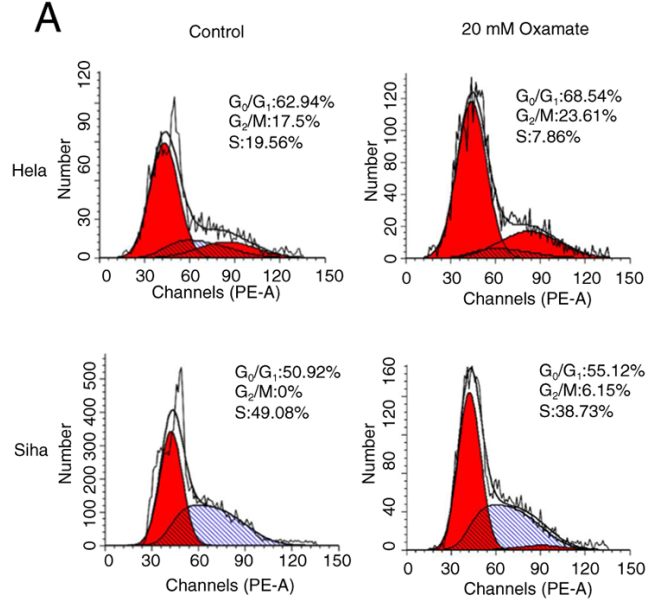

B
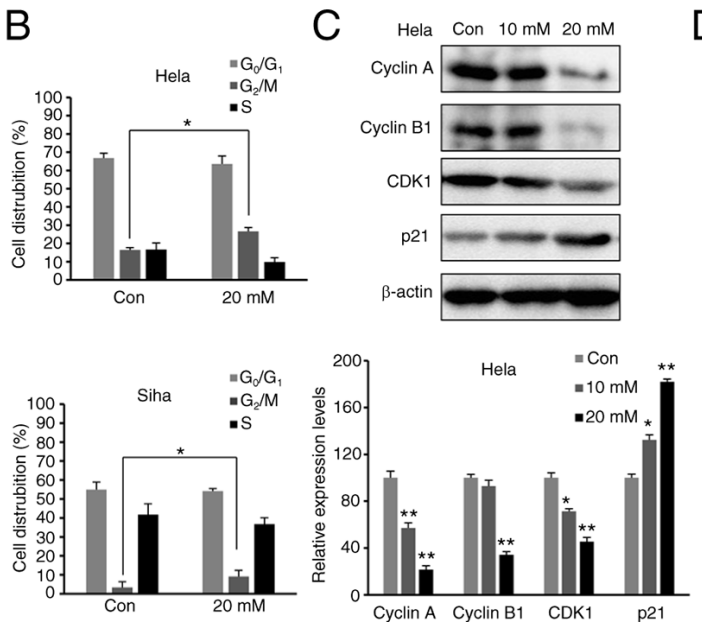

F
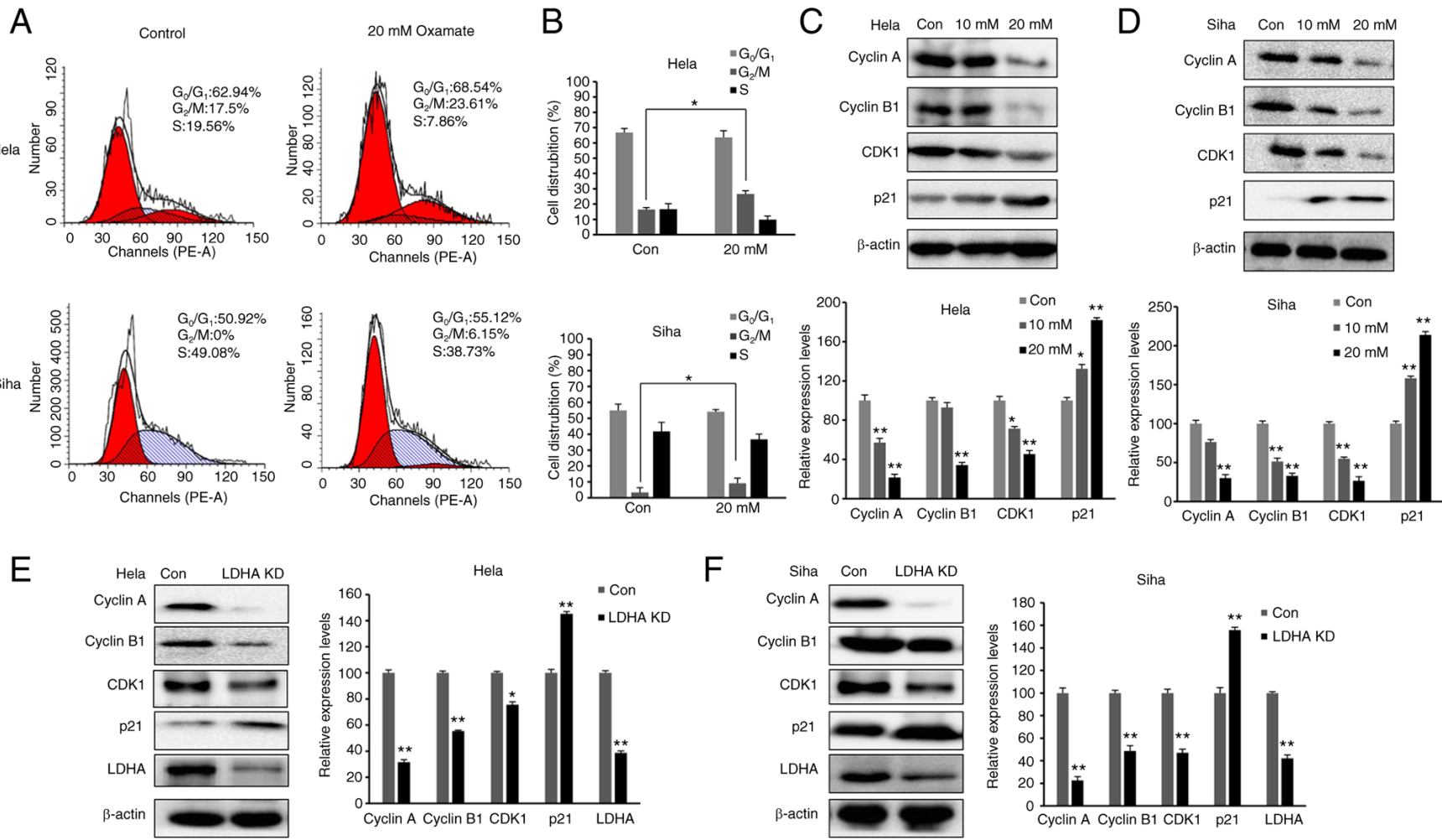

Figure 5. LDHA inhibition induces cell cycle arrest in $\mathrm{G}_{2} / \mathrm{M}$ phase in cervical squamous cell carcinoma and endocervical adenocarcinoma cells. (A) Flow cytometric analysis was performed to detect proliferation of $\mathrm{HeLa}$ and $\mathrm{SiHa}$ cells following treatment with oxamate for $48 \mathrm{~h}$. (B) Cell distribution analysis of each group. Western blot analysis was used to detect expression of Cyclin B1, Cyclin A, CDK1 and p21 in (C) HeLa and (D) SiHa cells following treatment with oxamate for $48 \mathrm{~h}$. Western blot analysis was used to detect expression of Cyclin B1, Cyclin A, CDK1 and p21 in LDHA KD (E) HeLa and (F) SiHa cells. ${ }^{*} \mathrm{P}<0.05,{ }^{* *} \mathrm{P}<0.01$ vs. con. Con, control; KD, knockdown; LDHA, lactate dehydrogenase A chain; CDK, cyclin-dependent kinase.

LDHA inhibition induces apoptosis via the mitochondrial pathway. The present study demonstrated that LDH inhibition impaired proliferation and increased the $\mathrm{G}_{2} / \mathrm{M}$ fraction in CESC cells. To determine whether LDHA inhibition induces apoptosis, cells were exposed to oxamate for $48 \mathrm{~h}$, then Annexin V/PI staining and flow cytometric analysis were performed. Following $48 \mathrm{~h}$ treatment with oxamate, the percentages of apoptotic cells significantly increased (Fig. 6A and B). Next, expression of apoptosis-associated proteins were detected by western blot analysis. Expression of cleaved-caspase-3 and -9 was significantly enhanced following treatment with oxamate for $48 \mathrm{~h}$ (Fig. 6C and D). Apoptosis-associated protein expression levels were compared between LDHA-knockdown CESC and control cells (Fig. 6E and F). Western blot results showed that higher expression of cleaved-caspase-3 and -9 was detected following knockdown of LDHA, supporting the results of oxamate treatment experiments. Protein levels of cytochrome $c$ in the cytoplasm and mitochondria were detected; cytochrome $c$ was released from mitochondria into the cytoplasm following LDHA inhibition (Fig. 6G and H). Taken together, these results indicated that LDHA inhibition induced apoptosis via the mitochondrial pathway in CESC cells.

LDHA inhibition induces cell cycle arrest and apoptosis via the JNK pathway. Multiple studies have indicated that mitogen-activated protein kinases (MAPKs), such as p38 and JNK, pathways are associated with cell proliferation, apoptosis and cell cycle progression $(40,41)$. As HeLa cells are the most commonly used cell model for cervical cancer, the present study investigated whether p38 or JNK pathways were involved in LDHA inhibition-mediated cell cycle arrest and apoptosis in HeLa cells. Western blot analysis (Fig. 7A) showed a significant increase in JNK phosphorylation in HeLa cells following treatment with oxamate, while there was no notable change in phosphorylation level of p38. The same results were observed following knockdown of LDHA (Fig. 7B).

To verify whether JNK signaling was required for inhibition of cell proliferation following LDHA knockdown or oxamate treatment, SP600125, a JNK inhibitor (42), was used to suppress JNK signaling in HeLa cells. SP600125 led to a significant decrease in JNK phosphorylation induced by oxamate treatment and LDHA knockdown (Fig. 7C and E). The present study investigated the regulatory effect of SP600125 on cell viability. SP600125 treatment significantly reversed the inhibitory effect on cell viability caused by LDHA knockdown and oxamate treatment (Fig. 7D and F). These findings indicated that the JNK pathway was involved in regulating apoptosis and cell cycle arrest induced by LDHA inhibition in HeLa cells.

\section{Discussion}

Increasing evidence indicates that aerobic glycolysis (Warburg effect) serves a key role in regulating proliferation and cell cycle changes, especially in cancer cells $(43,44)$. Given the key role of LDHA in aerobic glycolysis, the present study investigated the 
A
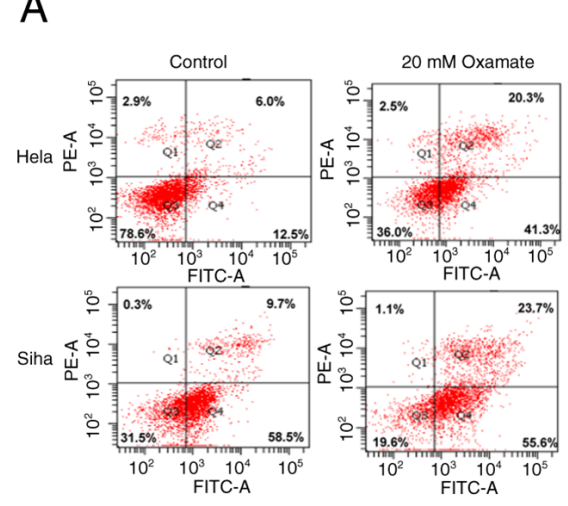

B

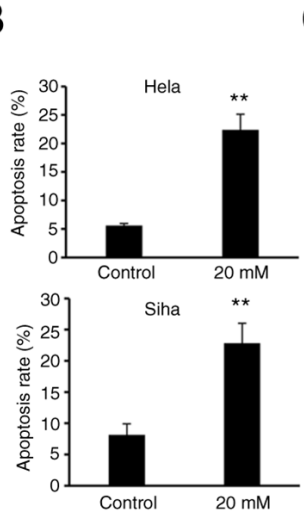

C

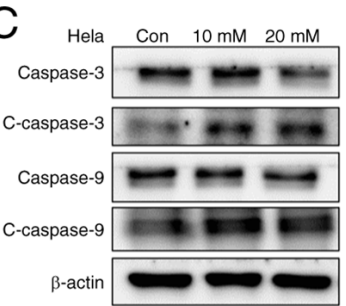

D
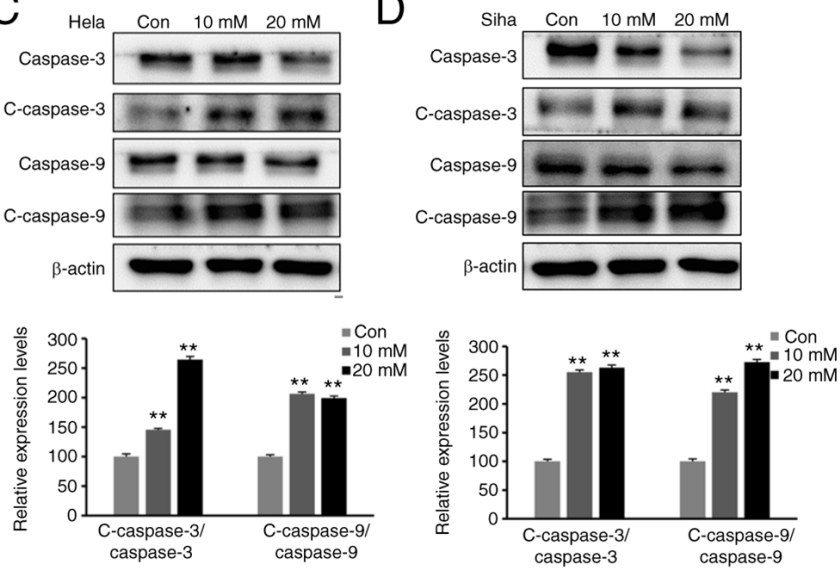

E

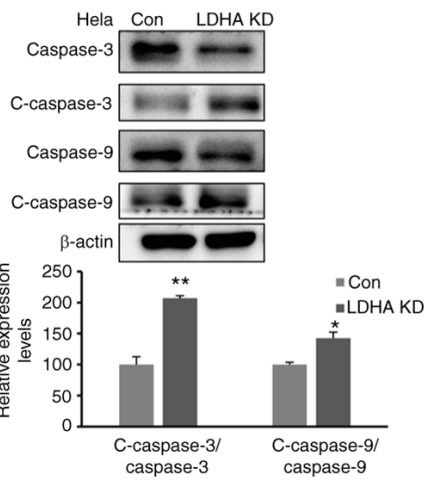

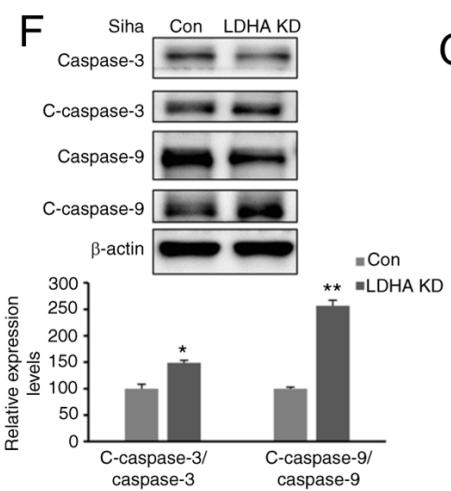

caspase-3
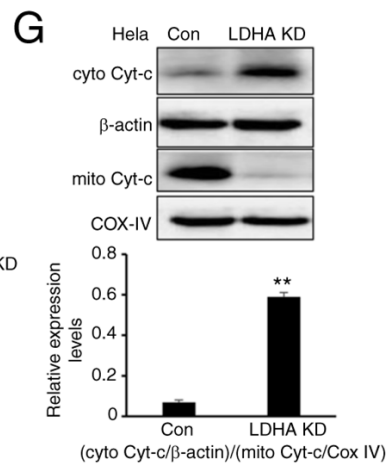

H Siha con LDHA KD

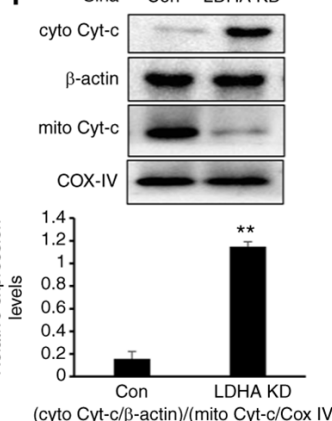

Figure 6. LDHA inhibition induces mitochondrial apoptosis. (A) Flow cytometric analysis was performed to detect apoptosis of HeLa and SiHa cells following treatment with oxamate for $48 \mathrm{~h}$. (B) Apoptosis rates of HeLa and SiHa cells were analyzed in each group. Western blot analysis was used to detect expression levels of c-caspase-3, caspase-3, c-caspase-9 and caspase-9 in (C) HeLa and (D) SiHa cells following treatment with oxamate for 48 h. Western blot analysis was used to detect expression of c-caspase-3, caspase-3, c-caspase-9 and caspase-9 in LDHA KD (E) HeLa and (F) SiHa cells. Enhanced Cyt-c release in LDHA KD (G) HeLa and (H) SiHa cells. Western blot analysis was used to detect levels of Cyt-c in the cytoplasm and mitochondria. ${ }^{*} \mathrm{P}<0.05$, ${ }^{* *} \mathrm{P}<0.01 \mathrm{vs}$. con. Con, control; KD, knockdown; c-, cleaved; cyto, cytosolic; mito, mitochondrial; Cyt-c, cytochrome $c$; LDHA, lactate dehydrogenase A chain; COX IV, cytochrome $c$ oxidase IV.

effect of LDHA inhibition on cell cycle progression, proliferation and apoptosis of cervical cancer cells and the underlying mechanism. LDHA knockdown resulted in increased apoptosis and cell cycle arrest and decreased in lactate production and glucose uptake, which revealed an oncogenic role of LDHA in cervical cancer and suggested that LDHA may be a potential therapeutic target against cervical cancer.

Normal cells generate energy via mitochondrial oxidative phosphorylation, while cancer cells primarily utilize glucose via glycolysis to produce energy, even under normoxic conditions; this phenomenon is known as the Warburg effect (6). The Warburg effect is one of the primary hallmarks of cancer cells. LDHA is a major subunit of LDH, a key enzyme involved in the Warburg effect (45). Previous studies revealed that LDHA expression was elevated in in most types of cancer cell $(46,47)$. Here, TCGA datasets showed that LDHA expression was upregulated in most types of tumor and higher LDHA gene expression was found in CESC compared with normal cervical tissue. Furthermore, LDHA was associated with poor prognosis in patients with cervical cancer. MPC1 is a key enzyme in mitochondrial pyruvate transport during oxidative phosphorylation (48). In certain types of cancer, MPC1 deficiency or inactivation accelerates aerobic glycolysis and malignant progression (49,50). LDHA levels were negatively correlated with MPC1, indicating that cervical cancer was aerobic glycolysis-dependent. The present study suggested that
LDHA may be a therapeutical target for cervical cancer. The present study investigated the effect of LDHA inhibition by oxamate or knockdown LDHA by shRNA in cervical cancer.

Given that LDHA serves an important role in Warburg effect, which provides a constant supply of metabolites necessary for cell proliferation and division, it was hypothesized that inhibition of LDHA regulates aerobic glycolysis and impairs cell proliferation in cervical cancer. Consistent with this hypothesis, knocking down expression of LDHA significantly suppressed viability, clone formation capacity and proliferation of HeLa and SiHa cells and decreased lactate production and glucose uptake. The same results were obtained following inhibition of LDHA activity by oxamate both in HeLa and SiHa cells. Notably, $10 \mathrm{mM}$ oxamate significantly decreased glucose uptake and ATP production; however the significant effect of $10 \mathrm{mM}$ oxamate on cell viability was less pronounced. This may be because abnormal metabolism is only one factor affecting proliferation of tumor cells; other factors, such as oncogene activation, genomic instability and inflammatory signals, also suppress apoptosis and promote cell survival (51). In addition, when aerobic glycolysis of tumor cells is inhibited, cells may increase use of other energy sources, such as glutamine, to compensate and prevent inhibition of proliferation (52). Both MTT and colony formation assay were used to test the effect of LDHA inhibition on cell proliferation; the inhibitory effect of LDHA knockdown detected by colony 
A

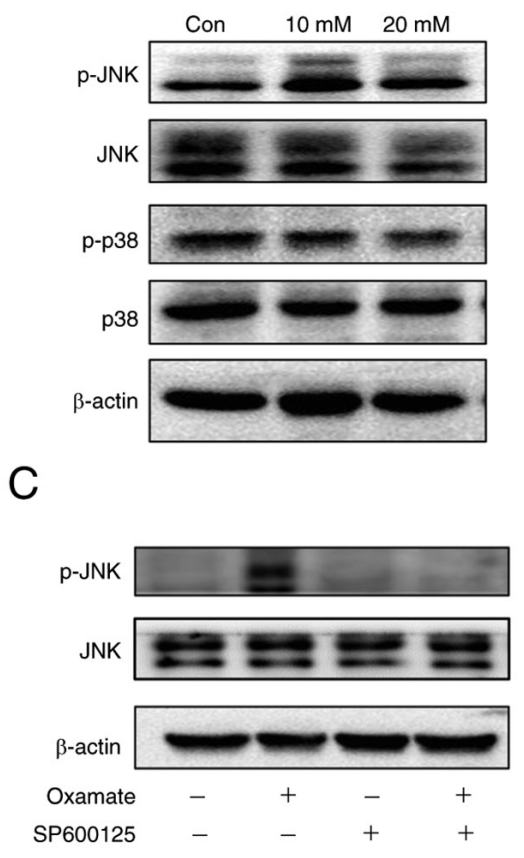

E

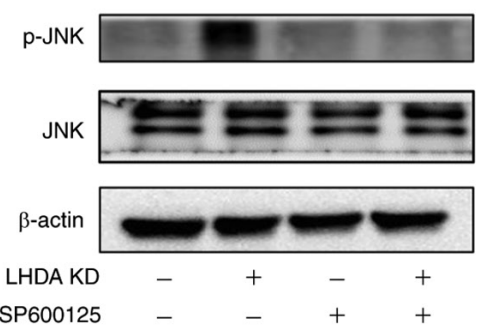

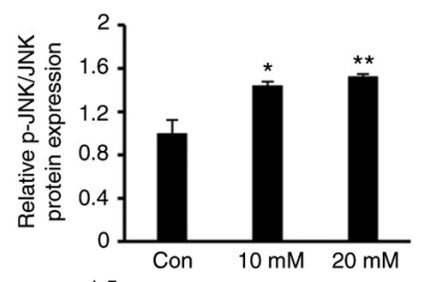
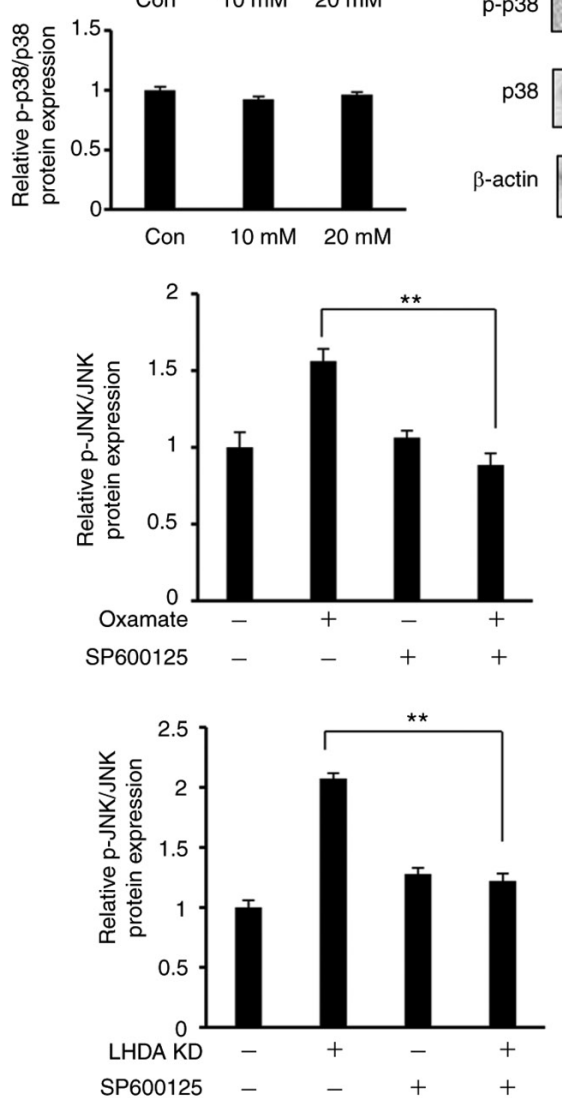

B
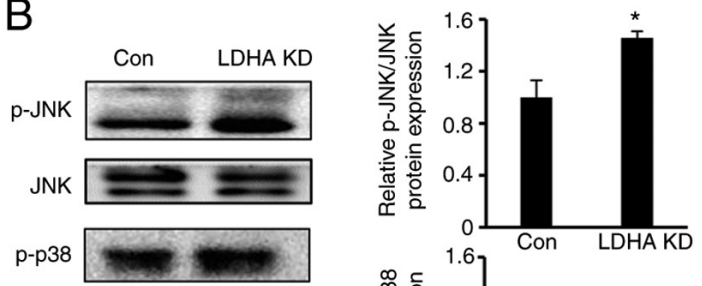

p38

$\beta$-actin

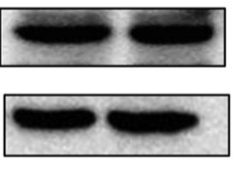

D

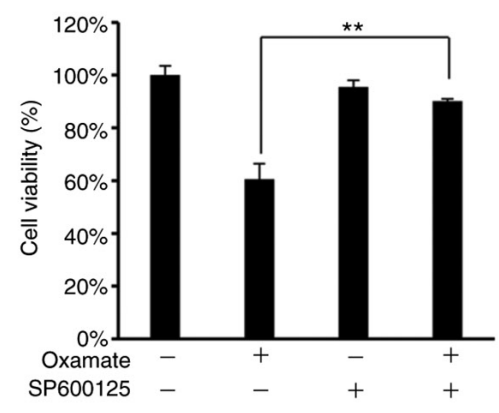

$\mathrm{F}$

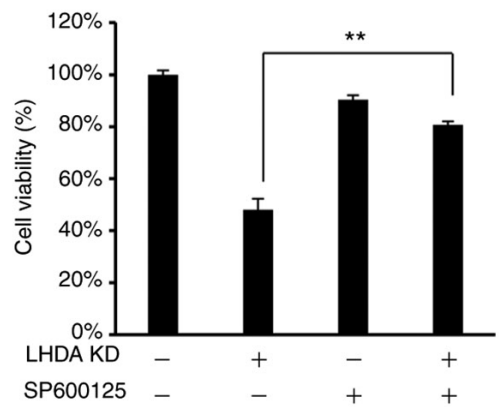

Figure 7. LDHA inhibition induces cell cycle arrest and apoptosis via the JNK signaling pathway. Western blot analysis was used to detect expression of p38, JNK, p-p38 and p-JNK in HeLa cells following (A) treatment with oxamate for $48 \mathrm{~h}$ or (B) LDHA KD. *P<0.05, ${ }^{* *} \mathrm{P}<0.01$ vs. con. (C) Phosphorylation of JNK and (D) viability were analyzed following treatment with oxamate, SP600125 (10 $\mu \mathrm{M})$ or oxamate + SP600125 in HeLa cells. ${ }^{* *} \mathrm{P}<0.01$ vs. oxamate. (E) Phosphorylation of JNK and (F) viability were analyzed in LDHA-knockdown HeLa cells following treatment with SP600125. ${ }^{* *}$ P $<0.01$ vs. KD. Con, control; KD, knockdown; LDHA, lactate dehydrogenase A chain; p-, phosphorylated.

formation assay was greater than that detected by MTT assay. This may be because there were only 1,000 cells/well in colony formation assay, there was insufficient cell-cell communication to protect against damage caused by oxamate or LDHA knockdown. Moreover, cells were exposed for longer period ( 1 week) compared with MTT assay.

Cyclins and CDKs are involved in regulating different phases of the cell cycle (53). Here, knockdown or inhibition of LDHA by oxamate induced $\mathrm{G}_{2} / \mathrm{M}$ cell cycle arrest, decreased expression levels of cyclin B1, cyclin A and CDK1 and increased expression levels of p21 in cervical cancer cells. The present results revealed that $\mathrm{G}_{2} / \mathrm{M}$ cell cycle arrest induced by inhibition of LDH was regulated by $\mathrm{p} 21$-mediated decreased activity of the CDK1/cyclin B1 kinase complex. A previous study also supports the hypothesis that decreased CDK1/cyclin $\mathrm{B} 1$ kinase complex activity triggers $\mathrm{G}_{2} / \mathrm{M}$ cell cycle arrest (54).

When LDHA is inhibited, increased levels of pyruvates enter the tricarboxylic acid cycle and mitochondrial oxidative phosphorylation pathway. The present finding that expression of LDHA was negatively correlated with MPC1, a key enzyme involved in oxidative phosphorylation in cervical cancer, supported this. However, in certain types of cancer cell, such as human gastric cancer SC-M1 and hepatocellular carcinoma HepG2 cells, mitochondria are dysfunctional and oxidative phosphorylation is impaired $(55,56)$. Oxidative phosphorylation is abnormally activated and more reactive oxygen species (ROS) are generated, resulting in mitochondrial apoptosis (57). In the present study, caspase-3 and caspase-9 activation was increased in CESC cells following inhibition of LDHA. In mitochondrial-dependent apoptosis, apoptotic proteins are activated by release of cytochrome $c$ (58). Here, cytochrome $c$ was released from mitochondria to the cytoplasm following LDHA knockdown. Whether caspase-3 and caspase-9 activation and cytochrome $c$ release induced by LDHA inhibition were due to increased levels of ROS requires confirmation. The present data indicated that LDH inhibition induced intrinsic mitochondrial apoptosis in cervical cancer cells.

LDHA inhibition results in cell cycle arrest and apoptosis. LDH inhibition by oxamate induced $\mathrm{G}_{2} / \mathrm{M}$ cell cycle arrest via downregulation of the $\mathrm{CDK} 1 / \mathrm{Cyclin} \mathrm{B} 1$ pathway and promoted 
apoptosis via enhancement of mitochondrial ROS generation in nasopharyngeal carcinoma cancer cells (22). Le et al (24) reported that LDHA inhibition resulted in decreased levels of ATP and ROS burst in lymphoma cancer cells, which led to apoptosis and $\mathrm{G}_{2} / \mathrm{M}$ arrest. Apoptosis and $\mathrm{G}_{2} / \mathrm{M}$ arrest were induced by LDHA inhibition via oxamate in non-small cell lung cancer (NSCLC) H1395 cells (37). Moreover, LDHA inhibition induced $\mathrm{G}_{0} / \mathrm{G}_{1}$ arrest and autophagy in NSCLC A549 cells (37). Other studies have found that LDHA inhibition suppressed migration and increases chemo- and radiosensitivity in cancer cells $(19,22,26,27)$. Consistent with these aforementioned reports, the present results showed that inhibition of LDHA induced $\mathrm{G}_{2} / \mathrm{M}$ cell cycle arrest and activated the mitochondrial apoptosis pathway in CESC cells. The MAPK pathway is a key pathway in regulating cell survival and proliferation (59). In the present study, JNK phosphorylation increased in HeLa cells following knockdown or inhibition of LDHA by oxamate. JNK inhibitor SP600125 effectively reversed cell death induced by $\mathrm{LDH}$ inhibition, indicating that JNK activation was required for LDHA inhibition-induced $\mathrm{G}_{2} / \mathrm{M}$ cell cycle arrest and apoptosis in cervical cancer cells.

To the best of our knowledge, the present study is the first to identify the role of LDHA in metabolism, viability, proliferation and apoptosis of cervical cancer cells. The present findings support the hypothesis that inhibition of LDHA may be an effective therapeutic strategy for regulating metabolism and tumor growth in cervical cancer. Future studies should investigate other key enzymes involved in the Warburg effect in cervical cancer, which may have similar effects as LDHA, and develop novel small molecule compounds specifically targeting LDHA.

\section{Acknowledgements}

Not applicable.

\section{Funding}

The present study was supported by Youth Foundation of The First Affiliated Hospital of Zhengzhou University (grant no. 71251$)$.

\section{Availability of data and materials}

The datasets used and/or analyzed during the current study are available from the corresponding author on reasonable request.

\section{Authors' contributions}

LM conceived the study and designed experiments. WZ performed experiments, analyzed data and wrote the manuscript. CW and YL performed experiments and analyzed data. $\mathrm{XH}$ and $\mathrm{CD}$ designed the experiments and wrote and revised the manuscript. WZ and CW confirm the authenticity of all the raw data. All authors have read and approved the final manuscript.

\section{Ethics approval and consent to participate}

Not applicable.

\section{Patient consent for publication}

Not applicable.

\section{Competing interests}

The authors declare that they have no competing interests.

\section{References}

1. Petrelli F, Ghidini A, Pedersini R, Cabiddu M, Borgonovo K, Parati MC, Ghilardi M, Amoroso V, Berruti A and Barni S: Comparative efficacy of palbociclib, ribociclib and abemaciclib for $\mathrm{ER}^{+}$metastatic breast cancer: An adjusted indirect analysis of randomized controlled trials. Breast Cancer Res Treat 174: 597-604, 2019

2. De Cicco P, Catani MV, Gasperi V, Sibilano M, Quaglietta M and Savini I: Nutrition and breast cancer: A literature review on prevention, treatment and recurrence. Nutrients 11: 1514, 2019.

3. Siegel RL, Miller KD and Jemal A: Cancer statistics, 2015. CA Cancer J Clin 65: 5-29, 2015.

4. Chen Q, Cao HZ and Zheng PS: LGR5 promotes the proliferation and tumor formation of cervical cancer cells through the Wnt/ $\beta$-catenin signaling pathway. Oncotarget 5: 9092-9105, 2014.

5. Li XQ, Bai YL, Zhang DL, Jiao HS and He RX: Euphornin reduces proliferation of human cervical adenocarcinoma $\mathrm{HeLa}$ cells through induction of apoptosis and G2/M cell cycle arrest. Onco Targets Ther 11: 4395-4405, 2018

6. Warburg O: On the origin of cancer cells. Science 123: 309-314, 1956.

7. Zu XL and Guppy M: Cancer metabolism: Facts, fantasy, and fiction. Biochem Biophys Res Commun 313: 459-465, 2004.

8. Pavlova NN and Thompson CB: The emerging hallmarks of cancer metabolism. Cell Metab 23: 27-47, 2016.

9. Potter M, Newport E and Morten KJ: The Warburg effect: 80 Years on. Biochem Soc Trans 44: 1499-1505, 2016.

10. Nicholas JA, Electricwala B, Lee LK and Johnson KM: Burden of relapsing-remitting multiple sclerosis on workers in the US: A cross-sectional analysis of survey data. BMC Neurol 19: 258, 2019.

11. Moreno-Sánchez R, Rodríguez-Enríquez S, Marín-Hernández A and Saavedra E: Energy metabolism in tumor cells. FEBS J 274: 1393-1418, 2007.

12. Liu W, Yu X, Zhou L, Li J, Li M, Li W and Gao F: Sinomenine inhibits non-small cell lung cancer via downregulation of hexokinases II-mediated aerobic glycolysis. Onco Targets Ther 13: 3209-3221, 2020

13. Tamgüney T, Zhang C, Fiedler D, Shokat K and Stokoe D: Analysis of 3-phosphoinositide-dependent kinase-1 signaling and function in ES cells. Exp Cell Res 314: 2299-2312, 2008.

14. Xie H, Valera VA, Merino MJ, Amato AM, Signoretti S, Linehan WM, Sukhatme VP and Seth P: LDH-A inhibition, a therapeutic strategy for treatment of hereditary leiomyomatosis and renal cell cancer. Mol Cancer Ther 8: 626-635, 2009.

15. Pelicano H, Martin DS, Xu RH and Huang P: Glycolysis inhibition for anticancer treatment. Oncogene 25: 4633-4646, 2006.

16. Choi YJ, Jeon JH and Oh JW: Critical combination of initial markers for predicting refractory Mycoplasma pneumoniae pneumonia in children: A case control study. Respir Res 20: 193, 2019.

17. Drent M, Cobben NA, Henderson RF, Wouters EF and van Dieijen-Visser M: Usefulness of lactate dehydrogenase and its isoenzymes as indicators of lung damage or inflammation. Eur Respir J 9: 1736-1742, 1996.

18. Jiang W, Zhou F, Li N, Li Q and Wang L: FOXM1-LDHA signaling promoted gastric cancer glycolytic phenotype and progression. Int J Clin Exp Pathol 8: 6756-6763, 2015.

19. Maftouh M, Avan A, Sciarrillo R, Granchi C, Leon LG, Rani R, Funel N, Smid K, Honeywell R, Boggi U, et al: Synergistic interaction of novel lactate dehydrogenase inhibitors with gemcitabine against pancreatic cancer cells in hypoxia. Br J Cancer 110: 172-182, 2014.

20. Shi M, Cui J, Du J, Wei D, Jia Z, Zhang J, Zhu Z, Gao Y and Xie K: A novel KLF4/LDHA signaling pathway regulates aerobic glycolysis in and progression of pancreatic cancer. Clin Cancer Res 20: 4370-4380, 2014. 
21. Sheng SL, Liu JJ, Dai YH, Sun XG, Xiong XP and Huang G: Knockdown of lactate dehydrogenase A suppresses tumor growth and metastasis of human hepatocellular carcinoma. FEBS J 279: 3898-3910, 2012

22. Zhai X, Yang Y, Wan J, Zhu R and Wu Y: Inhibition of LDH-A by oxamate induces $\mathrm{G} 2 / \mathrm{M}$ arrest, apoptosis and increases radiosensitivity in nasopharyngeal carcinoma cells. Oncol Rep 30: 2983-2991, 2013

23. Zhao YH, Zhou M, Liu H, Ding Y, Khong HT, Yu D, Fodstad O and Tan M: Upregulation of lactate dehydrogenase A by ErbB2 through heat shock factor 1 promotes breast cancer cell glycolysis and growth. Oncogene 28: 3689-3701, 2009.

24. Le A, Cooper CR, Gouw AM, Dinavahi R, Maitra A, Deck LM, Royer RE, Vander Jagt DL, Semenza GL and Dang CV: Inhibition of lactate dehydrogenase A induces oxidative stress and inhibits tumor progression. Proc Natl Acad Sci USA 107: 2037-2042, 2010

25. Wang ZY, Loo TY, Shen JG, Wang N, Wang DM, Yang DP, Mo SL, Guan XY and Chen JP: LDH-A silencing suppresses breast cancer tumorigenicity through induction of oxidative stress mediated mitochondrial pathway apoptosis. Breast Cancer Res Treat 131: 791-800, 2012

26. Zhou M, Zhao Y, Ding Y, Liu H, Liu Z, Fodstad O, Riker AI, Kamarajugadda S, Lu J, Owen LB, et al: Warburg effect in chemosensitivity: Targeting lactate dehydrogenase-A re-sensitizes taxol-resistant cancer cells to taxol. Mol Cancer 9: 33, 2010.

27. Zhao Y, Liu H, Liu Z, Ding Y, Ledoux SP, Wilson GL, Voellmy R, Lin Y, Lin W, Nahta R, et al: Overcoming trastuzumab resistance in breast cancer by targeting dysregulated glucose metabolism. Cancer Res 71: 4585-4597, 2011

28. Novoa WB, Winer AD, Glaid AJ and Schwert GW: Lactic dehydrogenase. V. Inhibition by oxamate and by oxalate. J Biol Chem 234: 1143-1148, 1959.

29. Ramanathan A, Wang C and Schreiber SL: Perturbational profiling of a cell-line model of tumorigenesis by using metabolic measurements. Proc Natl Acad Sci USA 102: 5992-5997, 2005.

30. Tang Z, Li C, Kang B, Gao G, Li C and Zhang Z: GEPIA: A web server for cancer and normal gene expression profiling and interactive analyses. Nucleic Acids Res 45: W98-W102, 2017.

31. Dong Y, Stewart T, Bai L, Li X, Xu T, Iliff J, Shi M, Zheng D, Yuan L, Wei T, et al: Coniferaldehyde attenuates Alzheimer's pathology via activation of Nrf2 and its targets. Theranostics 10 179-200, 2020

32. Zhang W, Gong J, Ding L, Zhang Z, Pan X, Chen X, Guo W, Zhang X, Yang X, Peng G, et al: Functional validation of a human GLUD2 variant in a murine model of Parkinson's disease. Cell Death Dis 11: 897, 2020.

33. Ma WQ, Sun XJ, Zhu Y and Liu NF: PDK4 promotes vascular calcification by interfering with autophagic activity and metabolic reprogramming. Cell Death Dis 11: 991, 2020.

34. Zhang WJ, Song ZB, Bao YL, Li WL, Yang XG, Wang Q, Yu CL, Sun LG, Huang YX and Li YX: Periplogenin induces necroptotic cell death through oxidative stress in $\mathrm{HaCaT}$ cells and ameliorates skin lesions in the TPA- and IMQ-induced psoriasis-like mouse models. Biochem Pharmacol 105: 66-79, 2016

35. Tan WX, Xu TM, Zhou ZL, Lv XJ, Liu J, Zhang WJ and Cui MH: TRP14 promotes resistance to cisplatin by inducing autophagy in ovarian cancer. Oncol Rep 42: 1343-1354, 2019.

36. An J, Zhang Y, He J, Zang Z, Zhou Z, Pei X, Zheng X, Zhang W, Yang $\mathrm{H}$ and Li S: Lactate dehydrogenase A promotes the invasion and proliferation of pituitary adenoma. Sci Rep 7: 4734, 2017.

37. Yang Y, Su D, Zhao L, Zhang D, Xu J, Wan J, Fan S and Chen M: Different effects of LDH-A inhibition by oxamate in non-small cell lung cancer cells. Oncotarget 5: 11886-11896, 2014.

38. Dayton TL, Jacks T and Vander Heiden MG: PKM2, cancer metabolism, and the road ahead. EMBO Rep 17: 1721-1730, 2016.

39. Malsy M, Gebhardt K, Gruber M, Wiese C, Graf B and Bundscherer A: Effects of ketamine, s-ketamine, and MK 801 on proliferation, apoptosis, and necrosis in pancreatic cancer cells. BMC Anesthesiol 15: 111, 2015.

40. Yim NH, Kim A, Liang C, Cho WK and Ma JY: Guibitang, a traditional herbal medicine, induces apoptotic death in A431 cells by regulating the activities of mitogen-activated protein kinases. BMC Complement Altern Med 14: 344, 2014.
41. Xie P, Horio F, Fujii I, Zhao J, Shinohara M and Matsukura M: A novel polysaccharide derived from algae extract inhibits cancer progression via JNK, not via the p38 MAPK signaling pathway. Int J Oncol 52: 1380-1390, 2018

42. Hao D, Li Y, Shi J and Jiang J: Baicalin alleviates chronic obstructive pulmonary disease through regulation of HSP72-mediated JNK pathway. Mol Med 27: 53, 2021.

43. Netea-Maier RT, Smit JWA and Netea MG: Metabolic changes in tumor cells and tumor-associated macrophages: A mutual relationship. Cancer Lett 413: 102-109, 2018.

44. Lu Y, Cheng J, Cai W, Zhuo H, Wu G and Cai J: Inhibition of circRNA circVPS33B reduces warburg effect and tumor growth through regulating the miR-873-5p/HNRNPK axis in infiltrative gastric cancer. Onco Targets Ther 14: 3095-3108, 2021.

45. Zdralević M, Brand A, Di Ianni L, Dettmer K, Reinders J, Singer K, Peter K, Schnell A, Bruss C, Decking SM, et al: Double genetic disruption of lactate dehydrogenases A and B is required to ablate the 'Warburg effect' restricting tumor growth to oxidative metabolism. J Biol Chem 293: 15947-15961, 2018.

46. Miao P, Sheng S, Sun X, Liu J and Huang G: Lactate dehydrogenase A in cancer: A promising target for diagnosis and therapy. IUBMB Life 65: 904-910, 2013.

47. Lu QY, Zhang L, Yee JK, Go VW and Lee WN: Metabolic consequences of LDHA inhibition by epigallocatechin gallate and oxamate in MIA $\mathrm{PaCa}-2$ pancreatic cancer cells Metabolomics 11: 71-80, 2015.

48. McCommis KS, Hodges WT, Bricker DK, Wisidagama DR, Compan V,Remedi MS, Thummel CS and Finck BN: An ancestral role for the mitochondrial pyruvate carrier in glucose-stimulated insulin secretion. Mol Metab 5: 602-614, 2016.

49. Li X, Han G, Li X, Kan Q, Fan Z, Li Y, Ji Y, Zhao J, Zhang M, Grigalavicius M, et al: Mitochondrial pyruvate carrier function determines cell stemness and metabolic reprogramming in cancer cells. Oncotarget 8: 46363-46380, 2017.

50. Li Y, Li X, Kan Q, Zhang M, Li X, Xu R, Wang J, Yu D, Goscinski MA, Wen JG, et al: Mitochondrial pyruvate carrier function is negatively linked to Warburg phenotype in vitro and malignant features in esophageal squamous cell carcinomas. Oncotarget 8: 1058-1073, 2017.

51. Hanahan D and Weinberg RA: Hallmarks of cancer: The next generation. Cell 144: 646-674, 2011.

52. Nossol C, Landgraf $P$, Kahlert S, Oster M, Isermann B, Dieterich DC, Wimmers K, Dänicke S and Rothkötter HJ: Deoxynivalenol affects cell metabolism and increases protein biosynthesis in intestinal porcine epithelial cells (IPEC-J2): DON increases protein biosynthesis. Toxins (Basel) 10: 464, 2018.

53. Pal HC and Katiyar SK: Cryptolepine, a plant alkaloid, inhibits the growth of non-melanoma skin cancer cells through inhibition of topoisomerase and induction of DNA damage. Molecules 21: $1758,2016$.

54. Lindqvist A, van Zon W, Karlsson Rosenthal C and Wolthuis RM: Cyclin B1-Cdk1 activation continues after centrosome separation to control mitotic progression. PLoS Biol 5: e123, 2007.

55. Hung WY, Huang KH, Wu CW, Chi CW, Kao HL, Li AF, Yin PH and Lee HC: Mitochondrial dysfunction promotes cell migration via reactive oxygen species-enhanced $\beta 5$-integrin expression in human gastric cancer SC-M1 cells. Biochim Biophys Acta 1820: $1102-1110,2012$

56. Guo Y, Zhang W, Yan YY, Ma CG, Wang X, Wang C and Zhao JL: Triterpenoid pristimerin induced HepG2 cells apoptosis through ROS-mediated mitochondrial dysfunction. J BUON 18: 477-485, 2013.

57. Bartz RR, Suliman HB and Piantadosi CA: Redox mechanisms of cardiomyocyte mitochondrial protection. Front Physiol 6: 291, 2015.

58. Jiang Q, Liu G, Wang X, Hou Y, Duan Y, Wu G, Yin Y and Yao K: Mitochondrial pathway is involved in the protective effects of alpha-ketoglutarate on hydrogen peroxide induced damage to intestinal cells. Oncotarget 8: 74820-74835, 2017.

59. Ades F and Metzger-Filho O: Targeting the cellular signaling: BRAF inhibition and beyond for the treatment of metastatic malignant melanoma. Dermatol Res Pract 2012: 259170, 2012.

(i) $\odot$ This work is licensed under a Creative Commons Attribution-NonCommercial-NoDerivatives 4.0 International (CC BY-NC-ND 4.0) License. 